\title{
Sea turtle hatchling production from Florida (USA) beaches, 2002-2012, with recommendations for analyzing hatching success
}

\author{
Beth Brost $^{1, *}$, Blair Witherington ${ }^{2}$, Anne Meylan ${ }^{1}$, Erin Leone $^{3}$, Llewellyn Ehrhart ${ }^{4}$, \\ Dean Bagley ${ }^{4}$
}

\author{
${ }^{1}$ Florida Fish and Wildlife Conservation Commission, Fish and Wildlife Research Institute, 100 8th Avenue Southeast, \\ St. Petersburg, Florida 33701, USA \\ ${ }^{2}$ Florida Fish and Wildlife Conservation Commission, Fish and Wildlife Research Institute, 9700 South A1A, \\ Melbourne Beach, Florida 32951, USA \\ ${ }^{3}$ Florida Fish and Wildlife Conservation Commission, Fish and Wildlife Research Institute, 1105 Southwest Williston Road, \\ Gainesville, Florida 32601, USA \\ ${ }^{4}$ Department of Biology, University of Central Florida, 4000 Central Florida Boulevard, Orlando, Florida 32816, USA
}

\begin{abstract}
We measured sea turtle hatchling production on 16 sea turtle nesting beaches $(219.6 \mathrm{~km})$ in Florida (USA) from 2002 to 2012. A standard protocol was used to sample 19701 loggerhead Caretta caretta, 3809 green turtle Chelonia mydas, and 664 leatherback Dermochelys coriacea nest contents, representing all Florida nesting beaches. We assessed (1) annual variation in hatching (hatched eggs/total eggs) and emergence (emerged hatchlings/total eggs) successes, (2) annual hatchling production, and (3) sources of egg and hatchling mortality. Emergence success rates were extrapolated to all Florida sea turtle nesting beaches using means weighted by each beach's nesting contribution. Weighted mean emergence success was $51.6 \%$ for loggerheads, $50.0 \%$ for green turtles, and $38.7 \%$ for leatherbacks. These estimates represent survivorship to the time hatchlings emerge from the nest. The estimated annual mean number of hatchlings produced on Florida beaches during the study period was 3528180 loggerheads (SD = $1155701), 568098$ green turtles $(\mathrm{SD}=327$ 156), and 33014 leatherbacks ( $\mathrm{SD}=17574)$. Beach erosion from storms and nest predation by mammals were the principal identified sources of egg and hatchling mortality. Average emergence success ranged from 38.8 to $65.0 \%$ between years and 41.8 to $61.7 \%$ between study beaches, suggesting that a single sample year or location would not adequately represent a sea turtle population in demographic analyses of multiple year classes. We provide recommendations for analyzing hatching success and present a method of analysis that allows the inclusion of partially depredated nests. These nests are typically excluded because the original clutch size and the number of eggs removed by predators may not be known.
\end{abstract}

KEY WORDS: Hatching success - Hatchling production - Survivorship - Caretta Chelonia · Dermochelys

\section{INTRODUCTION}

Sea turtle nesting on Florida (USA) beaches occurs at a globally significant scale. Florida hosts the largest number of nesting loggerhead turtles Caretta caretta

${ }^{*}$ Corresponding author: beth.brost@myfwc.com in the western hemisphere and has one of the largest assemblages of nesting green turtles Chelonia mydas in the wider Caribbean and Gulf of Mexico (Seminoff 2002, Witherington et al. 2006a,b). Peninsular Florida also has significant and increasing nesting by leath-

(C) The authors 2015. Open Access under Creative Commons by Attribution Licence. Use, distribution and reproduction are unrestricted. Authors and original publication must be credited. 
erbacks Dermochelys coriacea (Stewart et al. 2011). Because of the importance of Florida to sea turtle nesting, estimates of hatchling production from Florida provide important demographic rates for models that measure conservation success and assess recovery actions.

Sea turtle populations are considered under multiple listings to be at risk of extinction (Stewart \& Johnson 2006, Witherington et al. 2006a,b), but significant gaps in knowledge concerning each population prevent a complete understanding of their demographic status. The lack of information on stage-specific survivorship critically limits the demographic description of these populations. In this paper, we address survival rates for the earliest sea turtle life stages - eggs and hatchlings in the nestfocusing on the number of hatchlings that emerge from the nest unaided. Post-emergence mortality is not addressed.

Although hatching success (the proportion of eggs that result in hatchlings) is a commonly reported measure for sea turtle nests, it rarely represents stage-based survivorship in the population, because samples of nests are typically biased in space, time, and/or treatment. The most common sampling bias comes from study designs in which sample nests are manipulated as experimental subjects; nests are selected to compare hatching success between management practices (Steinitz et al. 1998, Abella et al. 2007, Tuttle \& Rostal 2010) or between experimental nest treatments (Honarvar et al. 2008) or to evaluate hatchery conditions (Blanck \& Sawyer 1981, Van de Merwe et al. 2005, Ozdemir \& Turkozan 2006). Many studies do present data on non-manipulated nests in situ, but apply only to a short time series (most commonly 1 nesting season) and for a narrow segment of a population's geographic range (Fowler 1979, Hewavisenthi \& Parmenter 2002, Foley et al. 2006, Tapilatu \& Tiwari 2007). Two studies that stand-out as representing population hatching success and as describing variation in this measure over a long time series focused on hawksbill Eretmochelys imbricata (Pérez-Castañeda et al. 2007) and green (Niethammer et al. 1997) turtles; the latter study took place on a single island on which the majority of the population's known nesting occurs.

Another important estimate that may be derived from evaluations of broad-scale emergence success is the rate of hatchling production from nests. Although this estimate does not include hatchling survivorship from nest to sea, it is useful as a proxy for hatchling recruitment. Hatchling production may be estimated from the number of hatchlings that emerge from a representative sample of nests, multiplied by the ratio of the number of eggs in all nests to the number of eggs in sample nests. Although hatchling production is occasionally estimated for segments of a population (Ehrhart \& Witherington 1987, Pike \& Stiner 2007), the scope of sampling required to determine production for an entire population typically hinders broader-scale estimates.

In this paper, we examine an 11 yr series of emergence success assessments for 16 beaches around Florida. For loggerheads, we provide estimates of annual hatchling production for the entire state, for 5 geographic regions within the state, and for 2 recovery units, Peninsular Florida and the Florida portion of the Northern Gulf of Mexico unit (NMFS \& USFWS 2008). These estimates span a principal part of the geographic range of the Northwest Atlantic Ocean Distinct Population Segment of loggerheads (Conant et al. 2009), of which $90 \%$ of the nesting occurs in the southeastern United States (data in Ehrhart et al. 2003). Hatching success assessments for green turtles and leatherbacks represent all of Florida.

The data result from the Statewide Nesting Beach Survey (SNBS) program, a sea turtle monitoring program managed by the Florida Fish and Wildlife Conservation Commission (FWC). The purpose of the SNBS program is to document the total distribution, seasonality, and abundance of sea turtle nests in Florida. Nesting data are collected by a network of individuals (including representatives of conservation organizations; local, state, and federal governmental personnel; academics; and consultants) who are under permit from the FWC to conduct research and conservation activities on marine turtles. The FWC, under a cooperative agreement with the U.S. Fish and Wildlife Service, issues the permits, provides training in nest survey techniques, and compiles nesting information. The existence of this network has made it possible to conduct a broad-scale, collective study of sea turtle hatchling production. The team monitors approximately 200 Florida beaches covering over $1300 \mathrm{~km}$.

We analyzed hatchling production data from 2002 through 2012, focusing on 3 measures: (1) the annual variation in hatching success (hatched eggs/total eggs) and emergence success (emerged hatchlings/ total eggs), (2) the number of hatchlings that emerged from Florida nests annually, and (3) the sources of egg and hatchling mortality. For 7 potential mortality factors we produced a ranking scheme that could benefit decisions on allocating management effort.

Finally, we highlighted the importance of representative sampling of nests, using precise methods to 
record clutch location and rigorously mark nests to produce unbiased estimates of emergence success. We also described a methodology that allows for the inclusion of emergence success from nests that have been predated.

\section{MATERIALS AND METHODS}

\section{Study beaches and sampling strategy}

We used data from 16 discrete study beaches where surveyors monitored sample nests for hatchling production (Table 1, Fig. 1), following a standardized protocol found in the FWC's Marine Turtle Conservation Guidelines (http://myfwc.com/media/418307/ Seaturtle_Guidelines_Sect2.pdf). The 16 beaches were selected because they have been surveyed as part of FWC's productivity assessment each year since its inception (2001) and because at least $90 \%$ of the nests were left in situ on those beaches. Surveyors at each beach site conducted nest counts and inventoried a spatially and temporally representative sample of nests to determine hatchling production. To obtain a representative sample, the FWC and surveyors selected a sampling interval based on the expected number of nests encountered (typically the average nest count for the preceding $5 \mathrm{yr}$ ) for each survey area. A sample interval was calculated to achieve the target of approximately 100 sample nests per beach per year. Thus, if approximately 1000 loggerhead nests were expected, every 10th loggerhead nest would be included in the study, giving every nest on the beach an opportunity to be a part of the sample over the course of the entire season. A target of 100 nests per beach was the minimal sample size required to detect a difference of $5 \%$ in hatching and emergence success rates between years, as determined with a power analysis using Student's $t$-test and Cohen's $d=0.4$ (alpha $=0.05$, beta $=0.20$ ). On beaches where surveyors expected fewer than 150 nests per year, all nests were included in the productivity assessment.

Because of an ongoing capture-mark-recapture research project, sample nests at 1 study beach (South Brevard County) were selected at oviposition (i.e. at night) rather than during the following diurnal survey. Clutch counts were conducted on nests marked at night in order to provide known clutch sizes prior to the occurrence of any disturbance and/or predation event. Sample nests on this beach were selected by establishing a weekly quota, based on historical nesting patterns that predicted how sample nests would be distributed in time and space.

Table 1. Study beaches in Florida, USA, and participating organizations. Species: Caretta caretta, Chelonia mydas, Dermochelys coriacea

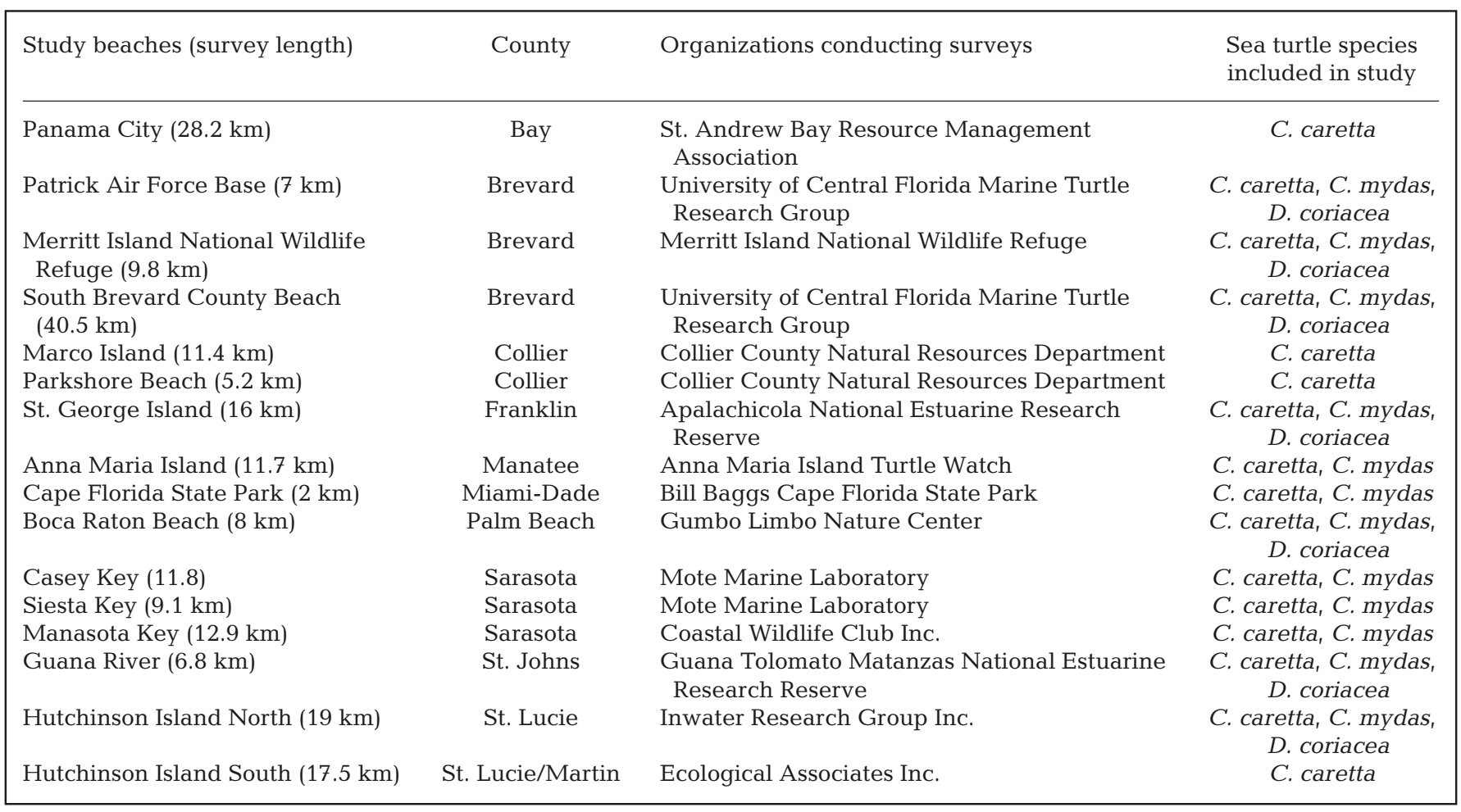




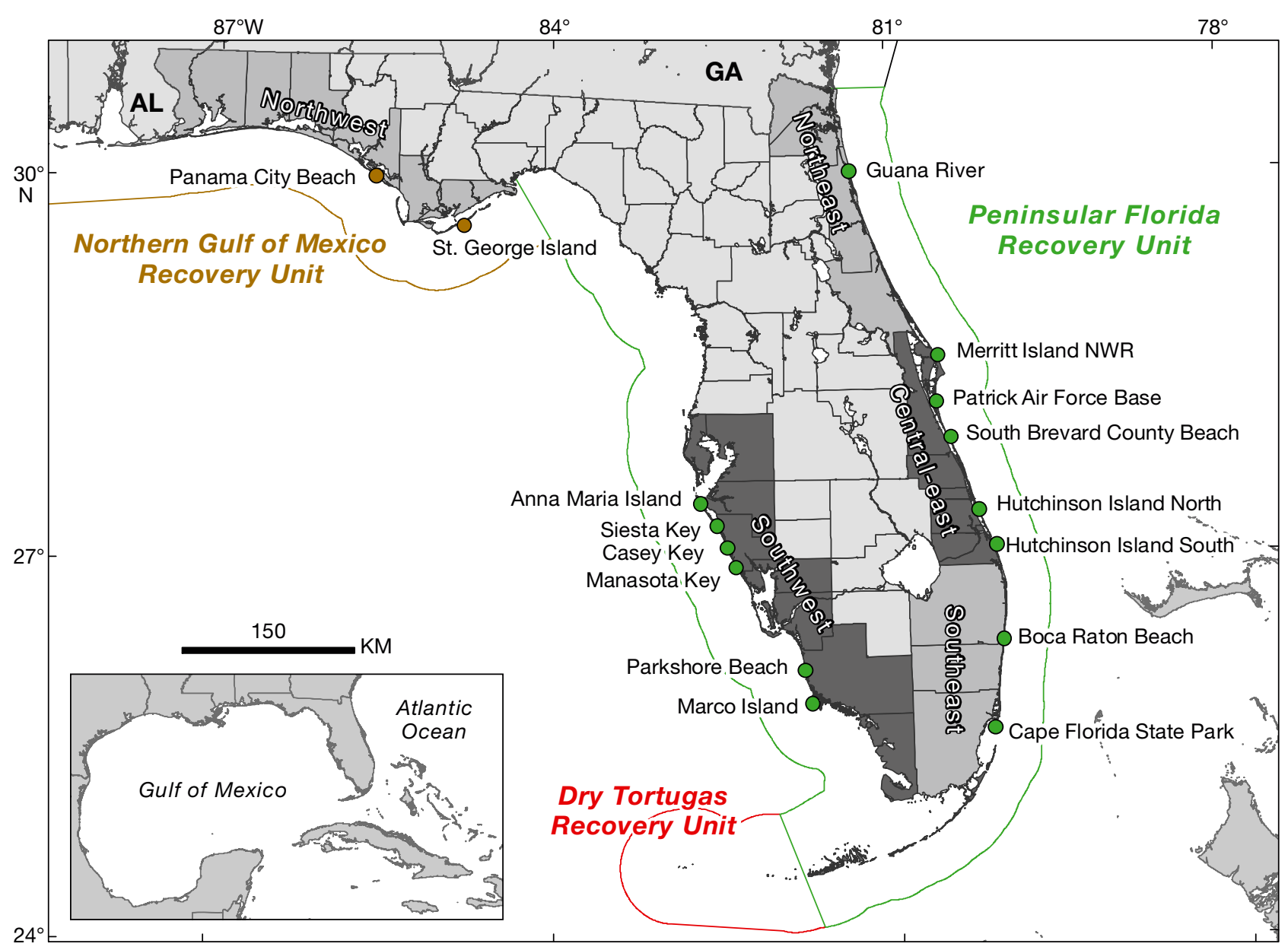

Fig. 1. Locations of the 16 study beaches in Florida, USA, used to represent sea turtle hatchling production for the state, regions (as described in Witherington et al. 2009), and loggerhead sea turtle recovery units (noted by outlining)

Except for the South Brevard County study beach, surveyors marked the location of clutches within $12 \mathrm{~h}$ of oviposition so that nests could be found and their contents inventoried once hatchlings had emerged. These marking methods had to withstand seasonal changes that typically occur on a beach and included measuring the distance between a clutch and 2 to 4 semi-permanent stakes driven into the sand at the base of the dune or on the dune crest. Surveyors verified clutch location using physical evidence left in the sand by the nesting turtle (e.g. a crater in the sand or 'body pit', evidence of covering the nest with the front flippers, etc.; Witherington et al. 2009). To find the exact location of the clutch, narrow test holes were hand-dug to find the topmost eggs of the clutch. The holes were then refilled with moist sand and lightly compacted by hand. So that results for selected nests would accurately represent all study beach nests, sampled and un-sampled nests were not treated differently. For example, a sample nest would be protected (e.g. screened or caged) from predators only if it would have also been protected had it not been selected as a sample nest.

We evaluated data from each sample nest for errors in inventory counts and other inconsistencies and excluded data that met any of 5 criteria: (1) the nest could not be located at inventory time, and the surveyor did not know the nest's fate; (2) notes indicated that the nest had been given special treatment because it was a sample nest; (3) the nest experienced partial washout from beach erosion during incubation (and an unknown number of eggs were lost); (4) a major disturbance (e.g. digging by a predator; erosion) occurred after hatchlings should have emerged but before the inventory was conducted; or (5) the nest had been relocated (because relocation might have introduced other egg-mortality factors [e.g. movement-induced mortality] that were not present for in situ nests). Excluded data represented $9.6 \%$ of loggerhead nests, $9.1 \%$ of green turtle nests, and $11.1 \%$ of leatherback nests, except in 2007 and 2008, when an average of $22 \%$ of the data for green turtle nests 
was discarded as a result of frequent storm tides that washed away nest markers and nest contents after incubation but prior to inventory. In addition, these data do not include loggerhead nests from northern gulf beaches in 2010 because of the region-wide translocation of nests by volunteers due to the MC 252 (BP Gulf) oil spill (Brennan 2013).

\section{Nest counts}

Surveyors on each study beach counted sea turtle nests throughout the nesting season following a standardized protocol found in FWC's Marine Turtle Conservation Guidelines (http://myfwc.com/media/ 418307/Seaturtle_Guidelines_Sect2.pdf). We defined a nest as having a clutch of eggs. Some error in our hatchling production estimates could have resulted from incorrect identification of nests. Witherington et al. (2009) estimated that the probability of a Florida surveyor correctly identifying a nest (that the nest counted actually had a clutch of eggs) was $96 \%$ (95\% CI: 0.92-0.99).

\section{Hatching and emergence success}

Based on observations of nests, post-incubation inventory of nest contents, and notes taken on conspicuous events affecting nests during incubation, surveyors collected the following information: species, egg deposition date, clutch size (if known), nest treatment (e.g. antipredator screen, relocation, no protection), and possible mortality events during incubation (e.g. predation with predator identified, poaching, tidal inundation, erosion). At the conclusion of incubation, surveyors inventoried nest contents following FWC Conservation Guidelines, which specify that the inventory be carried out $72 \mathrm{~h}$ after first sign of hatchling emergence (depression and/or hatchling tracks), or $70 \mathrm{~d}$ (for loggerheads and green turtles) or $80 \mathrm{~d}$ (for leatherbacks) post egg deposition. The inventory included recording the numbers of hatched eggs (shell fragments $>50 \%$ complete), live and dead hatchlings, and unhatched eggs. Unhatched eggs included pipped eggs (eggshell torn but hatchling not emerged from the eggshell), whole eggs, and damaged eggs (damaged by root penetration, predation, or other disturbance). These definitions were in keeping with techniques proposed by Miller (1999). For purposes of determining clutch size or evaluating hatching and emergence success, 'eggs' without yolk (yolkless eggs, or 'spacers') were not counted.
For nests that did not experience a major disturbance (events that removed eggs such as erosion, predation, etc.), we estimated clutch size as the sum of the number of unhatched eggs and shells from hatched eggs, recorded in post-incubation inventories of nest contents. We calculated hatching success (HS) and emergence success (ES) using the following formulas and definitions (Miller 1999):

$$
\begin{gathered}
\mathrm{HS}=S / C_{\mathrm{i}} \\
\mathrm{ES}=(S-R) / C_{\mathrm{i}}
\end{gathered}
$$

where $S$ is the number of empty shells ( $>50 \%$ intact, from Miller 1999) from which hatchlings emerged, $C_{\mathrm{i}}$ is the estimated clutch size derived from the nest inventory, and $R$ is the number of hatchlings remaining in the nest that did not emerge. Eggshell counts may deviate slightly from exact clutch size due to eggshell fragmentation. However, this is not typically a problem when inventories are conducted on a timely basis. Fowler (1979) estimated that accuracy in counting hatched shells ranged between 92 and $100 \%$.

We calculated the mean annual hatching and emergence success rates for sample nests on each of our 16 study beaches. Because the data set we analyzed had a large number of zeros from total nest failures, we also calculated median values to represent central tendency. This gave both parametric and nonparametric measures for hatching and emergence success rates and for hatchling production. To estimate the annual number of eggs laid per species for each study beach, we multiplied the total number of nests counted on each beach by an average clutch size calculated from 2424 loggerhead, 902 green turtle, and 44 leatherback nests at the South Brevard County study beach (2001-2009), where eggs were counted during or immediately after oviposition. For loggerhead and leatherback nests, no significant year-to-year differences were observed, so for our analysis we used the mean clutch size [loggerhead $(\bar{x}=114, \mathrm{SD}=23.8)$; leatherback $(\bar{x}=81, \mathrm{SD}=25)]$. Green turtle clutch sizes, however, did differ among years (ANOVA: $F_{7.793}=2.10, \mathrm{p}=0.042$ ). Because there were no green turtle clutch-size counts in 2002, we used the multiannual mean clutch size $(\bar{x}=128$, $\mathrm{SD}=22.9$ ) as a substitute for that year. For all other years, we used the annual mean green turtle clutch size, which ranged from 118 to 137 eggs.

In order to make nest evaluations as representative as possible, we devised a method that allowed us to estimate success in nests with major disturbances by mammalian predators. We developed proxy values for hatching and emergence success from nests of known clutch size at the South Brevard County 
beach, which had experienced predation events. For these proxy values, we used success rates calculated from nests preyed on (1) by mammals and (2) by both mammals and ghost crabs Ocypode quadrata. In applying these proxy rates to depredated nests, we used the hatching and emergence success rates with the higher standard error of the mean (SEM) to calculate a conservative overall average for study beaches on which some nests had been preyed on solely by mammals or a combination of mammals and ghost crabs. When no eggs or shells were encountered during the inventory of an apparently depredated nest, the nest was considered to have been entirely depredated and was assigned a hatching and emergence success of zero. Because only 2 occurrences of depredation by mammals occurred on leatherback nests with a known clutch size, we could not estimate a mean, so these nests were excluded from the analysis.

Partly eroded nests $(\sim 1 \%)$ were excluded from analyses except at South Brevard County beach, where initial clutch sizes were known. When storms were determined to have completely eroded the beach surrounding a sample nest and the nest contents could not be found, surveyors recorded zero success.

\section{Hatchling production}

Emergence success rate was used to estimate hatchling production by species for all Florida nesting beaches using the weighted mean emergence success of each sample beach based on the proportion of all Florida nests it represented. Annual hatchling production per species was estimated from the following equations:

and

$$
\mathrm{ES}_{\mathrm{F}}=\left(\sum\left[N_{\mathrm{sb}} \times \mathrm{ES}_{\mathrm{sb}}\right]\right) / N_{\mathrm{F}}
$$

$$
P_{\mathrm{F}}=\mathrm{ES}_{\mathrm{F}} \times\left(N_{\mathrm{F}} \times C\right)
$$

where $\mathrm{ES}_{\mathrm{F}}$ is the weighted mean annual emergence success for all Florida nests, $N_{\mathrm{sb}}$ is the annual nest count for each sample beach, $\mathrm{ES}_{\mathrm{sb}}$ is the mean annual emergence success for each sample beach, $N_{\mathrm{F}}$ is the annual nest count for all of Florida, $P_{\mathrm{F}}$ is the hatchling production estimate for all of Florida, and $C$ is the estimated clutch size.

Our expansion of hatchling production estimates to all of Florida nesting beaches required total nest counts for the state. These total counts came from the SNBS program, which comprises approximately 200 beaches. During the study period (2002-2012), participant survey effort covered nearly all known nesting beaches in Florida (Witherington et al. 2009; see also http://ocean.floridamarine.org/SeaTurtle/nesting/ FlexViewer/). The total length of nesting beach surveyed each year during the study period fluctuated no more than $1.5 \%$ from a mean of $1309.3 \mathrm{~km}$.

We analyzed hatching and emergence success rates separately for the 2 recovery units in which our study beaches were located: (1) Peninsular Florida Recovery Unit (includes 14 of our study beaches), defined as the nesting beaches from the Florida-Georgia state line through Pinellas County (excluding the islands west of Key West) and (2) Northern Gulf of Mexico Recovery Unit (includes 2 of our study beaches), defined as the nesting beaches from Franklin County in Florida through Texas (NMFS \& USFWS 2008) (Fig. 1).

\section{Mortality factors}

We developed generalized linear mixed models for loggerhead and green turtle nests, assuming a binomial distribution, to describe how mortality factors affected hatching and emergence rates. We incorporated 9 potential mortality factors (Table 2) as fixed factors, using the GLIMMIX procedure of SAS v.9.3 to perform the analyses. For our assessment, we focused on 7 factor groupings that were most easily recognizable by surveyors and that were most likely to have the greatest effect on mortality. Other factors were each reported for $<1 \%$ of sample nests.

In our original analysis of mortality factors, year was included as a random variable for green turtles and loggerheads. But this covariance term was estimated at zero for green turtles and so was dropped from the model for that species. We built additional generalized linear mixed models, each assuming a binomial distribution, to evaluate the impact of the fixed categorical factor of year on emergence and hatch rate for nests depredated by (1) ghost crabs, (2) raccoons, and (3) ghost crabs plus raccoons. When there was no effect of year, average hatch or emergence rate was estimated using an ESTIMATE statement. For these models, any year with fewer than 3 observed nests for the South Brevard study beach was removed.

\section{RESULTS}

\section{Sample representation}

We calculated hatching and emergence success, and estimated hatchling production based on inven- 
Table 2. Principal mortality factors reported for sea turtle nests at the South Brevard County Beach, Florida. Factors are ranked by their associated emergence success rates, 2002-2009, as estimated from generalized linear mixed models (see 'Materials and methods'). Other mortality factors (not shown) were reported in $<1 \%$ of the remaining nests. Nests with no reported mortality factors had an average hatching success rate of $75.4 \%$, which reflects cryptic factors such as infertility, pathogens, and/or undetected predation

\begin{tabular}{|c|c|c|c|}
\hline Reported mortality factors & $\begin{array}{l}\text { Frequency } \\
\text { of occurrence }\end{array}$ & $\begin{array}{l}\text { Hatching success } \\
(\%, \pm \text { SEM })\end{array}$ & $\begin{array}{c}\text { Emergence success } \\
(\%, \pm \text { SEM })\end{array}$ \\
\hline \multicolumn{4}{|l|}{ Caretta caretta $(\mathrm{n}=2697)$} \\
\hline None reported (mean intercept) & 1080 & $75.4( \pm 0.7)$ & $73.0( \pm 0.7)$ \\
\hline Ghost crab & 944 & $64.8( \pm 1.8)$ & $62.7( \pm 1.8)$ \\
\hline Roots & 92 & $53.3( \pm 3.4)$ & $51.8( \pm 3.4)$ \\
\hline Accretion & 2 & $51.5( \pm 18.2)$ & $51.4( \pm 18.6)$ \\
\hline Inundation & 83 & $47.4( \pm 3.5)$ & $45.2( \pm 3.6)$ \\
\hline Partial mammalian depredation & 95 & $36.7( \pm 3.5)$ & $35.7( \pm 3.5)$ \\
\hline Partial mammalian plus ghost crab depredation & 26 & $26.1( \pm 4.5)$ & $25.4( \pm 4.5)$ \\
\hline Partial wash outs & 23 & $25.7( \pm 5.9)$ & $25.3( \pm 6.0)$ \\
\hline Complete wash outs & 308 & 0.0 & 0.0 \\
\hline Complete depredation & 44 & 0.0 & 0.0 \\
\hline \multicolumn{4}{|l|}{ Chelonia mydas $(\mathrm{n}=992)$} \\
\hline None reported (mean intercept) & 323 & $69.0( \pm 1.3)$ & $66.8( \pm 1.3)$ \\
\hline Ghost crab & 371 & $57.7( \pm 3.2)$ & $55.9( \pm 3.2)$ \\
\hline Roots & 83 & $53.5( \pm 4.3)$ & $52.3( \pm 4.3)$ \\
\hline Inundation & 20 & $40.7( \pm 7.1)$ & $34.3( \pm 7.2)$ \\
\hline Partial mammalian depredation & 60 & $36.8( \pm 4.7)$ & $25.8( \pm 4.7)$ \\
\hline Partial wash outs & 10 & $26.0( \pm 9.3)$ & $26.0( \pm 9.4)$ \\
\hline Partial mammalian plus ghost crab depredation & 17 & $25.5( \pm 6.5)$ & $24.9( \pm 6.6)$ \\
\hline Accretion & 2 & $18.6( \pm 19.3)$ & $18.5( \pm 19.5)$ \\
\hline Complete wash outs & 87 & 0.0 & 0.0 \\
\hline Complete depredation & 19 & 0.0 & 0.0 \\
\hline
\end{tabular}

tory assessments of 19701 loggerhead nests, 3809 green turtle nests, and 664 leatherback nests (Table 3). The average number of nests sampled annually over the 11 yr was 1791 (SEM = 732) for loggerheads, 346 $(\mathrm{SEM}=73)$ for green turtles, and $60(\mathrm{SEM}=27)$ for leatherbacks. The proportion of Florida (total statewide) nests occurring on the 16 study beaches averaged $42 \%$ for loggerheads, $39 \%$ for green turtles, and $13 \%$ for leatherbacks.

\section{Hatching and emergence success}

Hatching and emergence success rates were calculated for the 16 study beaches (Table 3). The mean emergence success rates were $51.9 \%$ (SEM = 4.4) for loggerheads, $51.4 \%(\mathrm{SEM}=7.9)$ for green turtles, and $37.4 \%($ SEM = 7.7) for leatherbacks. An additional analysis determined the average hatching and emergence success rates for nests that had at least 1 hatched egg. These were 70.1\% (SEM = 4.5) and $66.9 \%(\mathrm{SEM}=4.4)$ for loggerheads; $67.7 \%$ $(\mathrm{SEM}=8.0)$ and $63.4 \%(\mathrm{SEM}=8.0)$ for green turtles; and $48.1 \%(\mathrm{SEM}=7.0)$ and $51.0 \%(\mathrm{SEM}=7.2)$ for leatherbacks.
We estimated a grand weighted mean for hatching and emergence success by species representing all Florida nesting beaches from 2002 to 2012 (Table 4). The weighted mean emergence success rates were $51.6 \%$ for loggerheads, $50.0 \%$ for green turtles, and $38.7 \%$ for leatherbacks. To represent annual changes in emergence success, we plotted annual weighted means for each species (Fig. 2).

Each of the 16 study beaches had a sufficient number of sample nests to allow examination of annual trends in loggerhead emergence success by beach location $(\bar{X}=114$ sample nests per beach per year, SEM $=8.33$ ). A plot of annual weighted mean hatchling emergence success for loggerhead nests at each of the 16 study beaches (Fig. 3) revealed high variation both between years and between study beaches.

\section{Hatchling production}

Using the weighted average emergence success from the 16 study beaches, we estimated that 3528180 loggerhead, 568098 green, and 33014 leatherback hatchlings were produced annually on Florida beaches (Table 4, Fig. 4). We also estimated 
Table 3. Hatching and emergence success rates and annual hatchling production from in situ sea turtle nests on 16 study beaches in Florida, 2002-2012. No. of hatchlings produced only includes those hatchlings that emerged from nests unaided; it does not include live hatchlings found in nests at time of excavation

\begin{tabular}{|c|c|c|c|c|c|c|c|}
\hline \multirow[t]{2}{*}{ Year } & \multirow{2}{*}{$\begin{array}{l}\text { Total no. of nests (no. } \\
\text { inventoried, \% of total) }\end{array}$} & \multicolumn{2}{|c|}{ Hatching success (\%) } & \multicolumn{2}{|c|}{ Emergence success (\%) } & \multicolumn{2}{|c|}{ No. of hatchlings produced } \\
\hline & & Mean $( \pm$ SEM $)$ & Median & Mean $( \pm$ SEM $)$ & Median & Mean & Median \\
\hline \multicolumn{8}{|c|}{ Caretta caretta } \\
\hline 2002 & $27707(1402,5.1)$ & $61.0( \pm 4.6)$ & 74.0 & $59.3( \pm 4.4)$ & 71.6 & 1593148 & 1823464 \\
\hline 2003 & $26601(1411,5.3)$ & $60.8( \pm 6.2)$ & 73.1 & $58.3( \pm 6.0)$ & 69.7 & 1781392 & 2041188 \\
\hline 2004 & $19667(1145,5.8)$ & $43.2( \pm 5.2)$ & 35.7 & $40.9( \pm 5.0)$ & 33.4 & 870887 & 690534 \\
\hline 2005 & $22911(1154,5.0)$ & $44.5( \pm 4.9)$ & 46.7 & $41.6( \pm 4.8)$ & 39.9 & 1273415 & 1462579 \\
\hline 2006 & $20617(1205,5.8)$ & $69.9( \pm 5.3)$ & 82.6 & $67.7( \pm 5.0)$ & 79.9 & 1526800 & 1824585 \\
\hline 2007 & $17988(1369,7.6)$ & $59.5( \pm 5.2)$ & 68.6 & $56.9( \pm 5.1)$ & 64.7 & 1154840 & 1365923 \\
\hline 2008 & $25001(2060,8.2)$ & $52.3( \pm 4.9)$ & 55.4 & $49.5( \pm 4.8)$ & 51.1 & 1344818 & 1559694 \\
\hline 2009 & $20237(1862,9.2)$ & $57.4( \pm 4.1)$ & 63.1 & $54.9( \pm 4.2)$ & 59.8 & 1140255 & 1282402 \\
\hline $2010^{a}$ & $29314(2319,7.9)$ & $52.8( \pm 2.8)$ & 59.8 & $50.2( \pm 2.8)$ & 57.1 & 1609201 & 1833184 \\
\hline $2011^{b}$ & $27223(2197,8.1)$ & $51.4( \pm 4.2)$ & 60.2 & $49.1( \pm 4.1)$ & 56.1 & 1420136 & 1620630 \\
\hline 2012 & $39699(3577,9.0)$ & $44.2( \pm 2.9)$ & 40.3 & $42.4( \pm 2.7)$ & 38.1 & 2657256 & 2959619 \\
\hline Average & $25179(1791,7.1)$ & $54.3( \pm 4.6)$ & 60.0 & $51.9( \pm 4.4)$ & 56.5 & 1488377 & 1678528 \\
\hline \multicolumn{8}{|c|}{ Chelonia mydas } \\
\hline 2002 & $3877(303,7.8)$ & $68.0( \pm 7.3)$ & 73.9 & $52.7( \pm 6.2)$ & 67.7 & 300944 & 338784 \\
\hline 2003 & $738(231,31.3)$ & $44.0( \pm 8.9)$ & 45.8 & $42.7( \pm 8.4)$ & 44.3 & 48033 & 55029 \\
\hline 2004 & $1292(249,19.3)$ & $35.5( \pm 15.9)$ & 29.4 & $34.2( \pm 15.2)$ & 24.5 & 34649 & 625 \\
\hline 2005 & $4198(421,10.0)$ & $43.7( \pm 7.5)$ & 42.4 & $40.7( \pm 7.3)$ & 39.6 & 289601 & 323030 \\
\hline 2006 & $1914(356,18.6)$ & $70.2( \pm 3.6)$ & 75.6 & $68.4( \pm 3.6)$ & 73.1 & 138458 & 161273 \\
\hline 2007 & $4974(437,8.8)$ & $60.6( \pm 6.1)$ & 67.7 & $55.0( \pm 6.8)$ & 62.8 & 354036 & 399157 \\
\hline 2008 & $3616(350,9.7)$ & $47.5( \pm 9.7)$ & 48.6 & $43.6( \pm 8.1)$ & 44.6 & 164917 & 100623 \\
\hline 2009 & $1548(299,19.3)$ & $68.5( \pm 7.7)$ & 73.5 & $63.6( \pm 7.8)$ & 68.4 & 99701 & 110207 \\
\hline $2010^{\mathrm{a}}$ & $5108(431,8.4)$ & $47.9( \pm 7.6)$ & 50.7 & $43.4( \pm 7.1)$ & 44.8 & 357006 & 406684 \\
\hline $2011^{b}$ & $6449(321,5.0)$ & $58.9( \pm 10.2)$ & 68.4 & $54.6( \pm 10.9)$ & 62.7 & 446226 & 553320 \\
\hline 2012 & $4009(411,10.3)$ & $58.8( \pm 6.1)$ & 62.6 & $56.8( \pm 6.0)$ & 58.7 & 289892 & 336730 \\
\hline Average & $3429(346,10.1)$ & $54.9( \pm 8.2)$ & 58.1 & $51.4( \pm 7.9)$ & 53.7 & 229406 & 253224 \\
\hline \multicolumn{8}{|c|}{ Dermochelys coriacea } \\
\hline 2002 & $32(25,78.1)$ & $22.5( \pm 2.0)$ & 25.3 & $21.4( \pm 2.2)$ & 24.3 & 964 & 1081 \\
\hline 2003 & $157(68,43.3)$ & $34.0( \pm 10.9)$ & 35.4 & $31.4( \pm 11.0)$ & 31.4 & 3597 & 2790 \\
\hline 2004 & $66(31,47.0)$ & $35.6( \pm 3.7)$ & 36.6 & $28.8( \pm 4.5)$ & 30.7 & 1723 & 1860 \\
\hline 2005 & $125(60,48.0)$ & $51.4( \pm 9.8)$ & 48.9 & $45.7( \pm 10.0)$ & 43.2 & 3786 & 3315 \\
\hline 2006 & $94(55,58.5)$ & $67.8( \pm 4.8)$ & 69.6 & $64.2( \pm 4.8)$ & 65.5 & 4465 & 4512 \\
\hline 2007 & $300(96,32.0)$ & $36.6( \pm 5.0)$ & 29.5 & $32.8( \pm 4.7)$ & 25.3 & 7693 & 5044 \\
\hline 2008 & $33(28,84.8)$ & $33.3( \pm 6.8)$ & 36.3 & $32.5( \pm 6.7)$ & 35.3 & 1202 & 1302 \\
\hline 2009 & $65(57,87.7)$ & $41.9( \pm 17.7)$ & 40.3 & $39.4( \pm 17.1)$ & 37.0 & 2453 & 2598 \\
\hline $2010^{\mathrm{a}}$ & $174(55,31.6)$ & $34.0( \pm 7.3)$ & 27.9 & $28.1( \pm 7.2)$ & 22.6 & 4245 & 3181 \\
\hline $2011^{b}$ & $208(80,38.5)$ & $42.8( \pm 7.2)$ & 42.3 & $38.9( \pm 7.3)$ & 40.9 & 5661 & 4961 \\
\hline 2012 & $230(109,47.4)$ & $53.1( \pm 5.0)$ & 57.3 & $48.7( \pm 5.0)$ & 52.0 & 8437 & 9481 \\
\hline Average & $135(60,44.4)$ & $41.2( \pm 7.7)$ & 40.8 & $37.4( \pm 7.7)$ & 37.1 & 4021 & 3648 \\
\hline
\end{tabular}

annual hatchling production for 2 of Florida's loggerhead recovery units (Table 5, Fig. 1). For the Peninsular Florida Recovery Unit, the mean annual number of hatchlings produced was 3485236 , and for the Northern Gulf of Mexico (Florida only) Recovery Unit, 33625 hatchlings were produced. Linear relationships between annual hatchling production and annual nest counts were positive for loggerheads $\left(\mathrm{R}^{2}=0.84, \mathrm{p}<0.001\right)$, green turtles $\left(\mathrm{R}^{2}=0.93, \mathrm{p}<\right.$ $0.001)$, and leatherbacks $\left(R^{2}=0.82, p=0.001\right)$ (Fig. 4). Years with strongly negative residuals (i.e. for which hatchling production was less than that modeled from nest counts) were years in which mean hatching and emergence success were lowest (Table 3).

\section{Mortality factors}

Data from sample nests at the South Brevard County study beach were sufficient to allow analysis of factors contributing to mortality for loggerhead and green turtle nests (Table 2). Mean emergence 
Table 4. Estimated hatchling production from in situ sea turtle nests in Florida, 2002-2012, based on weighted mean emergence success rates for 16 study beaches. No. of hatchlings produced statewide only includes those hatchlings that emerged from nests unaided; it does not include live hatchlings found in nests at time of excavation

\begin{tabular}{|c|c|c|c|c|c|c|c|}
\hline \multirow[t]{2}{*}{ Year } & \multirow{2}{*}{$\begin{array}{l}\text { Statewide nests } \\
\text { represented by } \\
\text { sample }(\%)\end{array}$} & \multicolumn{2}{|c|}{$\begin{array}{l}\text { Weighted hatching } \\
\text { success (\%) }\end{array}$} & \multicolumn{2}{|c|}{$\begin{array}{c}\text { Weighted emergence } \\
\text { success }(\%)\end{array}$} & \multicolumn{2}{|c|}{$\begin{array}{l}\text { No. of hatchlings } \\
\text { produced statewide }\end{array}$} \\
\hline & & Mean & Median & Mean & Median & Mean & Median \\
\hline \multicolumn{8}{|c|}{ Caretta caretta } \\
\hline 2002 & 45.8 & 51.8 & 59.8 & 50.4 & 57.7 & 3481270 & 3984545 \\
\hline 2003 & 44.1 & 60.1 & 69.3 & 58.7 & 67.3 & 4042670 & 4632249 \\
\hline 2004 & 43.7 & 40.3 & 31.5 & 38.8 & 30.8 & 1993251 & 1580465 \\
\hline 2005 & 45.7 & 51.2 & 60.4 & 48.8 & 56.0 & 2789164 & 3203490 \\
\hline 2006 & 42.7 & 66.9 & 79.9 & 65.0 & 77.6 & 3575765 & 4273177 \\
\hline 2007 & 41.1 & 57.7 & 68.9 & 56.3 & 66.6 & 2807876 & 3321103 \\
\hline 2008 & 41.7 & 48.6 & 56.7 & 47.2 & 54.7 & 3228349 & 3744177 \\
\hline 2009 & 39.6 & 51.7 & 58.1 & 49.4 & 55.6 & 2880922 & 3240066 \\
\hline $2010^{\mathrm{a}}$ & 40.5 & 52.0 & 60.4 & 48.2 & 54.9 & 3969863 & 4522426 \\
\hline $2011^{\mathrm{b}}$ & 40.4 & 47.7 & 55.9 & 45.8 & 52.2 & 3518962 & 4015766 \\
\hline 2012 & 40.7 & 59.8 & 66.6 & 58.7 & 65.4 & 6521886 & 7263998 \\
\hline Average & 42.3 & 53.4 & 60.7 & 51.6 & 58.1 & 3528180 & 3980133 \\
\hline \multicolumn{8}{|c|}{ Chelonia mydas } \\
\hline 2002 & 42.6 & 61.8 & 69.0 & 60.6 & 68.3 & 706057 & 794836 \\
\hline 2003 & 33.2 & 53.9 & 63.5 & 51.7 & 59.2 & 144491 & 165534 \\
\hline 2004 & 36.3 & 20.8 & 1.7 & 19.9 & 0.4 & 95364 & 1720 \\
\hline 2005 & 43.8 & 57.3 & 64.5 & 55.2 & 61.6 & 661019 & 737320 \\
\hline 2006 & 38.7 & 54.7 & 64.9 & 52.8 & 61.5 & 358225 & 417254 \\
\hline 2007 & 39.2 & 58.8 & 65.5 & 56.9 & 64.2 & 904166 & 1019400 \\
\hline 2008 & 39.3 & 36.2 & 24.2 & 35.1 & 21.4 & 419590 & 256010 \\
\hline 2009 & 34.8 & 54.1 & 59.7 & 51.5 & 57.0 & 286544 & 316738 \\
\hline $2010^{\mathrm{a}}$ & 38.8 & 57.7 & 66.7 & 55.9 & 63.7 & 920612 & 1048717 \\
\hline $2011^{b}$ & 42.1 & 55.5 & 70.0 & 54.1 & 67.0 & 1059414 & 1313675 \\
\hline 2012 & 41.8 & 57.6 & 68.1 & 56.5 & 65.6 & 693601 & 805666 \\
\hline Average & 39.1 & 51.7 & 56.2 & 50.0 & 53.6 & 568098 & 625170 \\
\hline \multicolumn{8}{|c|}{ Dermochelys coriacea } \\
\hline 2002 & 5.6 & 39.1 & 43.2 & 37.2 & 41.7 & 17314 & 19418 \\
\hline 2003 & 19.0 & 30.7 & 25.2 & 28.3 & 21.9 & 18949 & 14694 \\
\hline 2004 & 14.0 & 36.9 & 38.7 & 32.2 & 34.8 & 12325 & 13304 \\
\hline 2005 & 16.9 & 43.1 & 39.0 & 37.4 & 32.7 & 22385 & 19601 \\
\hline 2006 & 17.4 & 62.6 & 62.1 & 58.6 & 59.3 & 25601 & 25869 \\
\hline 2007 & 21.0 & 38.4 & 28.2 & 31.7 & 20.8 & 36565 & 23978 \\
\hline 2008 & 4.6 & 45.8 & 49.3 & 45.0 & 48.7 & 26332 & 28531 \\
\hline 2009 & 3.7 & 49.8 & 55.1 & 46.6 & 49.3 & 65591 & 69468 \\
\hline $2010^{\mathrm{a}}$ & 13.2 & 32.9 & 25.1 & 30.1 & 22.6 & 32153 & 24097 \\
\hline $2011^{b}$ & 12.6 & 35.4 & 30.2 & 33.6 & 29.4 & 44826 & 39283 \\
\hline 2012 & 13.8 & 47.8 & 54.1 & 45.3 & 50.9 & 61113 & 68672 \\
\hline Average & 12.9 & 42.1 & 40.9 & 38.7 & 37.5 & 33014 & 31538 \\
\hline
\end{tabular}

success when no mortality factor was reported, a condition that included undetected factors, was $73 \%$ for loggerhead nests and $67 \%$ for green turtle nests.

Emergence success rates for loggerhead and green turtle nests varied with mortality factor (Table 2). For both species, effects such as erosion (washouts) and inundation caused by rough sea conditions were important contributors to egg mortality. Emergence success for nests that experienced partial washout was $25.3 \%( \pm 6.0)$ for loggerheads and $26.0 \%( \pm 9.4)$ for green turtles. For both species, sample size for partial wash outs was small and the event occurred rarely on the other sample beaches (Table 2); thus, we did not develop proxy values (as we did for mammalian predation) to use in calculating hatching and emergence success for the other 15 study beaches. Predation by mammals was an important mortality factor for loggerheads and green turtles, reducing 


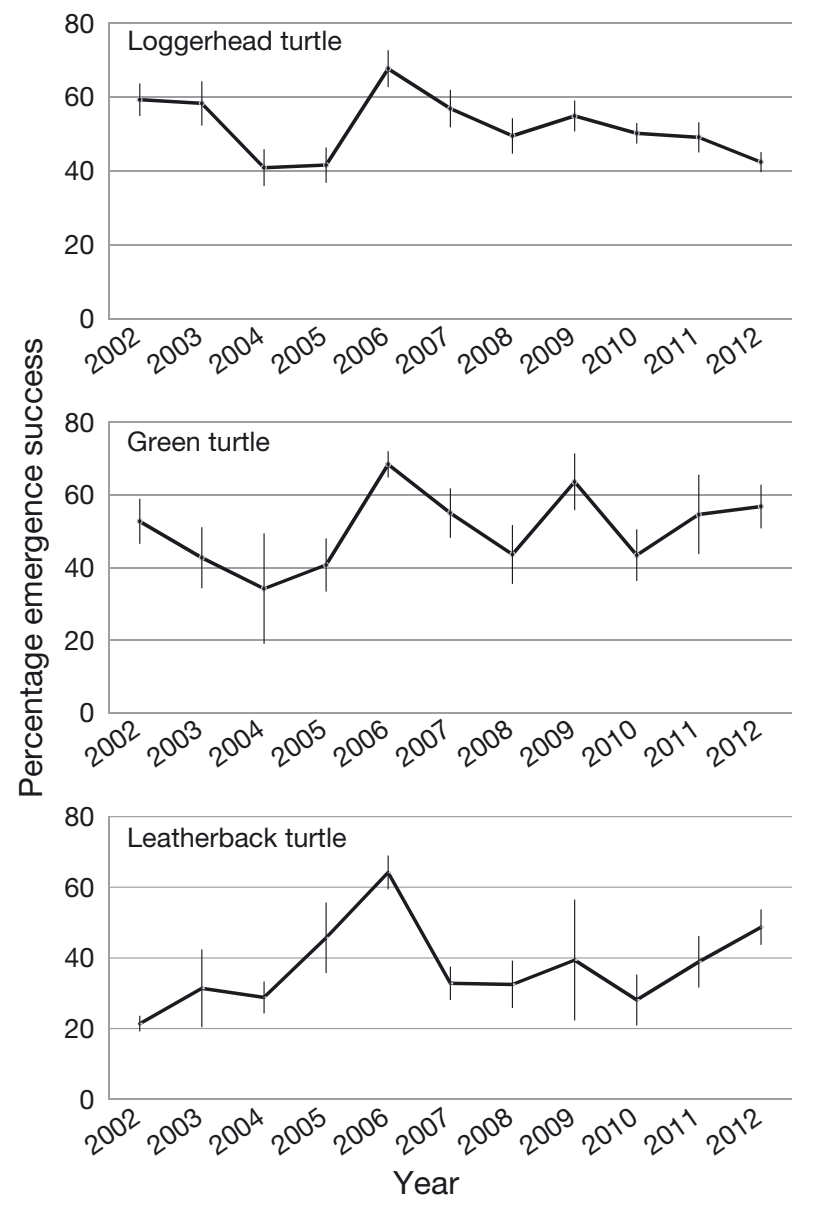

Fig. 2. Caretta caretta, Chelonia mydas, and Dermochelys coriacea. Annual mean sea turtle hatchling emergence success, weighted by nest counts, at 16 representative Florida study beaches. Means are displayed with vertical lines that describe \pm 1 SEM

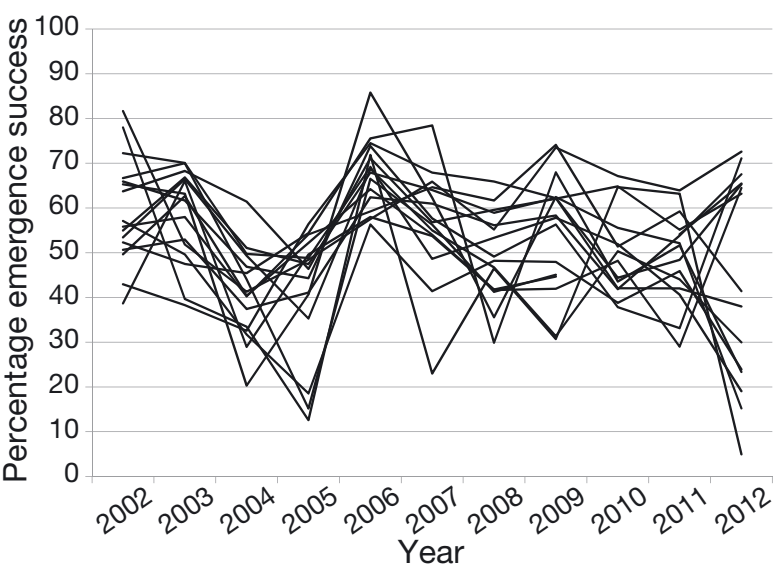

Fig. 3. Caretta caretta, Chelonia mydas, and Dermochelys coriacea. Annual mean hatchling emergence success, weighted by nest counts, for loggerhead nests at 16 representative Florida study beaches (Table 1). Each line represents the annual trend for a study beach
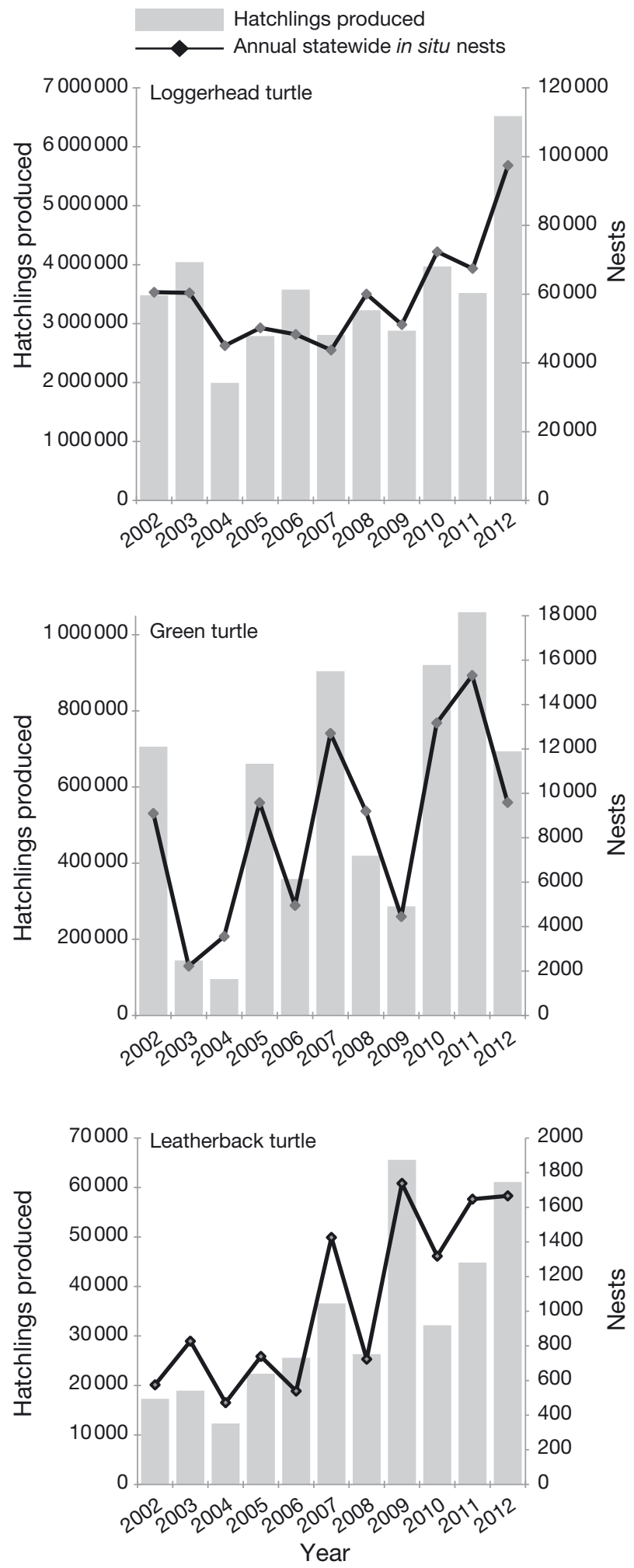

Fig. 4. Caretta caretta, Chelonia mydas, and Dermochelys coriacea. Estimated total annual sea turtle hatchling production at Florida nesting beaches versus total annual nest counts. Hatchling production was based on weighted mean emergence success rates from 16 representative study beaches 
Table 5. Estimated loggerhead Caretta caretta hatching production from in situ nests in the Peninsular Florida Recovery Unit and the Florida portion of the Northern Gulf of Mexico Recovery Unit, 2002-2012. No. of hatchlings produced only includes those hatchlings that emerged from nests unaided; it does not include live hatchlings found in nests at time of excavation

\begin{tabular}{|c|c|c|c|c|c|c|c|}
\hline \multirow[t]{2}{*}{ Year } & \multirow[t]{2}{*}{$\begin{array}{l}\text { No. of nests } \\
\text { inventoried }\end{array}$} & \multicolumn{2}{|c|}{$\begin{array}{l}\text { Weighted hatching } \\
\text { success }(\%)\end{array}$} & \multicolumn{2}{|c|}{$\begin{array}{l}\text { Weighted emergence } \\
\text { success }(\%)\end{array}$} & \multicolumn{2}{|c|}{$\begin{array}{c}\text { No. of hatchlings produced } \\
\text { in recovery unit }\end{array}$} \\
\hline & & Mean & Median & Mean & Median & Mean & Median \\
\hline \multicolumn{8}{|c|}{ Peninsular Florida Recovery Unit } \\
\hline 2002 & 1304 & 51.7 & 59.7 & 50.3 & 57.6 & 3440878 & 3939545 \\
\hline 2003 & 1275 & 59.9 & 69.1 & 58.6 & 67.2 & 3975976 & 4554687 \\
\hline 2004 & 1024 & 40.2 & 31.4 & 38.8 & 30.7 & 1956399 & 1551762 \\
\hline 2005 & 1027 & 51.3 & 60.7 & 48.9 & 56.3 & 2768689 & 3189991 \\
\hline 2006 & 1129 & 66.9 & 79.9 & 64.9 & 77.6 & 3538595 & 4228696 \\
\hline 2007 & 1300 & 57.7 & 68.9 & 56.3 & 66.6 & 2778851 & 3285342 \\
\hline 2008 & 1882 & 48.7 & 57.1 & 47.3 & 55.1 & 3192132 & 3723623 \\
\hline 2009 & 1729 & 51.9 & 58.4 & 49.5 & 55.8 & 2838242 & 3199239 \\
\hline 2010 & 2319 & 52.0 & 60.4 & 48.2 & 54.9 & 3927045 & 4473648 \\
\hline $2011^{\mathrm{a}}$ & 2048 & 47.7 & 55.8 & 45.7 & 52.1 & 3470402 & 3954529 \\
\hline 2012 & 3274 & 60.2 & 67.1 & 59.1 & 65.9 & 6450383 & 7195825 \\
\hline Average & 1665 & 53.5 & 60.8 & 51.6 & 58.2 & 3485236 & 3936081 \\
\hline \multicolumn{8}{|c|}{ Northern Gulf of Mexico (Florida only) Recovery Unit ${ }^{b}$} \\
\hline 2002 & 96 & 68.5 & 91.4 & 67.7 & 90.5 & 41550 & 55530 \\
\hline 2003 & 135 & 69.6 & 88.5 & 68.9 & 87.4 & 55472 & 70379 \\
\hline 2004 & 121 & 43.4 & 35.2 & 42.8 & 34.1 & 30613 & 24445 \\
\hline 2005 & 127 & 15.5 & 0.0 & 14.9 & 0.0 & 8146 & 0 \\
\hline 2006 & 78 & 67.9 & 83.1 & 66.9 & 83.0 & 35549 & 44071 \\
\hline 2007 & 69 & 55.6 & 79.0 & 54.4 & 78.0 & 26101 & 37440 \\
\hline 2008 & 177 & 42.4 & 4.7 & 41.5 & 3.7 & 33090 & 2912 \\
\hline 2009 & 131 & 40.0 & 28.1 & 33.1 & 15.7 & 39388 & 31555 \\
\hline 2011 & 149 & 55.6 & 80.3 & 53.1 & 74.5 & 46620 & 65436 \\
\hline 2012 & 303 & 14.0 & 0.0 & 12.2 & 0.0 & 19727 & 0 \\
\hline Average & 139 & 47.3 & 49.0 & 45.6 & 46.7 & 33625 & 33177 \\
\hline
\end{tabular}

emergence success $39 \%$ in loggerhead nests and $32 \%$ in green turtles, compared with nests for which no mortality factors were reported.

Sample size for loggerhead nests was sufficiently large for each of the 5 regions (northeast, $\mathrm{n}=527$; central east, $\mathrm{n}=5674$; southeast, $\mathrm{n}=1807$; southwest, $\mathrm{n}=8789$; and northwest, $\mathrm{n}=1484 ;$ Fig. 1 ) of Florida to allow regional analysis of mortality factors (Fig. 5). For all 5 regions, at least $60 \%$ of the nests experienced no reported mortality, although regional differences were detected.

\section{DISCUSSION}

\section{Estimates of survivorship and hatchling production}

Our methods addressed the challenge of using egg survivorship and hatchling production data to estimate some vital demographic rates of geographically widespread sea turtle populations. In addition to point estimates for loggerhead, green turtle, and leatherback nests, we also showed important variation in space and time. For all 3 species, annual variation in egg survivorship, as measured by emergence success (Fig. 2), showed that a single year of sampling would not adequately represent the population in demographic analyses of multiple year classes. Similarly, variation between sample beaches (Fig. 3) indicated that a single beach was unlikely to adequately represent emergence success for a species with a broad nesting range.

We attempted to achieve population-wide representation. The 16 Florida study beaches we report on represented all the regions of Florida, an area that hosts approximately $90 \%$ of all loggerheads nesting in the Northwest Atlantic Ocean Distinct Population Segment (data in Ehrhart et al. 2003) defined by Conant et al. (2009). Florida also hosts nearly $100 \%$ of nesting green turtles and leatherbacks in the con- 


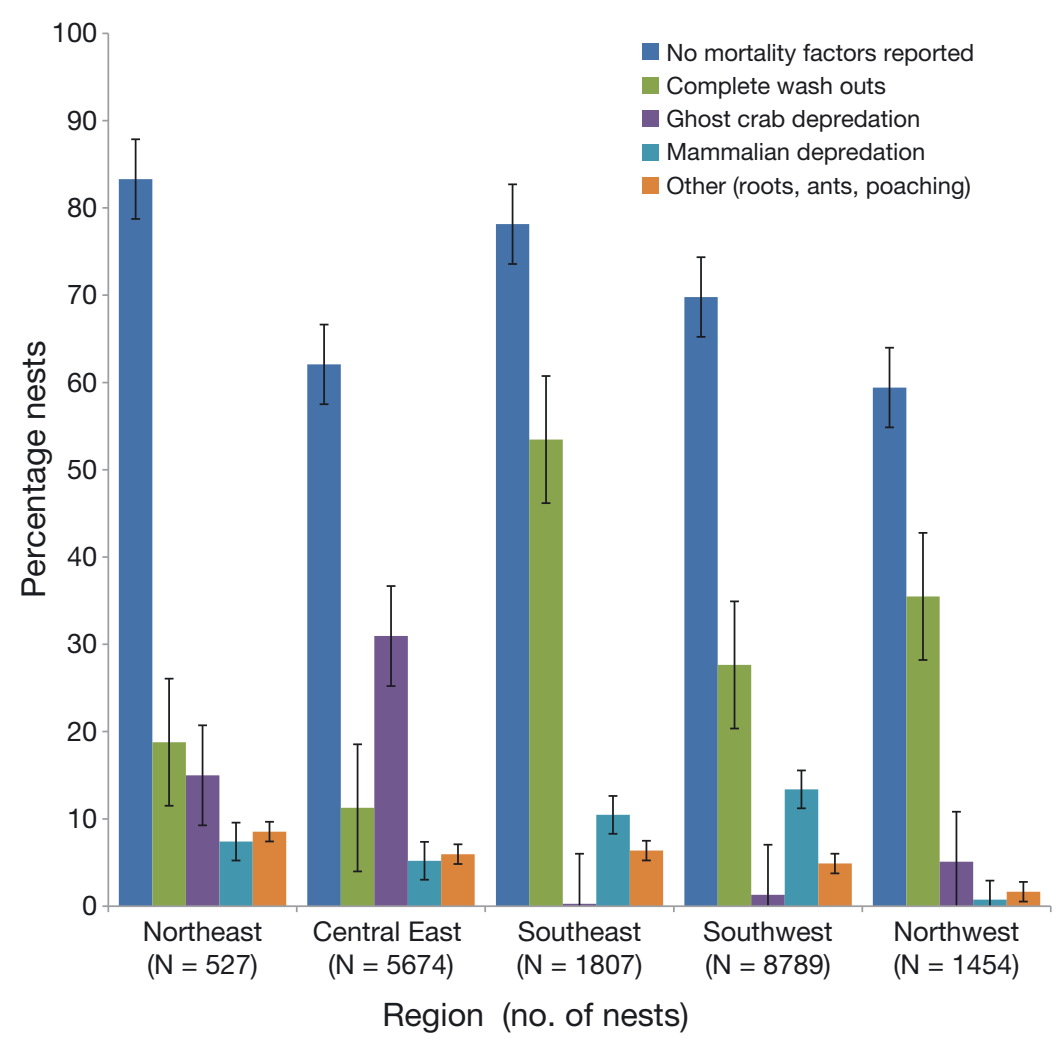

Fig. 5. Percentage of loggerhead Caretta caretta nests affected by various mortality factors, by region, based on 16 representative Florida study beaches, 2002-2012. Means are displayed with vertical lines describing \pm 1 SEM

mean hatching success in Florida loggerhead nests that had at least 1 hatched egg (overall mean hatching success $=70.1 \%, \mathrm{SEM}=4.5)$.

Foley et al. (2006) reported mean hatching $(68.9 \%)$ and emergence success rates $(68.6 \%)$ for loggerheads nesting on low-relief mangrove islands in the Ten Thousand Islands in southwest Florida in 1993 to 1994. Although a direct comparison with these results would not be appropriate because of differences in the temporal and spatial scopes of the studies, we note that we would expect our success rates $(53.4 \%$ for hatching and $51.6 \%$ for emergence) to be lower if only because our analysis included predated nests, whereas the Foley et al. (2006) study did not. In the Foley study, 19 of 90 nests were removed from the sample because they had been predated.

Our method of choosing every nth nest discovered during daily nest counts is one way to achieve a sample representative of an entire season and an entire study beach. Workers may be tempted to sample nests in another way that would fit in with project logis-

tinental United States. The 11 yr time series encompassed 4 loggerhead remigration cohorts (assuming a $2.7 \mathrm{yr}$ interval; Witherington et al. 2006b) and 5 green turtle and leatherback remigration cohorts (assuming 2 yr intervals; Witherington et al. 2006a, Eckert et al. 2012). The data series also spanned several tropical cyclone events. The time series, however, might be considered short, in that the $11 \mathrm{yr}$ of the study were part of a period for which the Atlantic Multidecadal Oscillation departure was largely positive, which may correspond with frequent tropical cyclone formation (www.esrl.noaa.gov/psd/data/climateindices/ list/).

Our estimates of egg survivorship could be expected to differ from other published values, because each nesting beach and each season has unique contributions of factors that influence egg mortality. A $19 \mathrm{yr}$ time series of loggerhead hatching success from Zakynthos, Greece (Margaritoulis 2005), described mean annual hatching success ranging from 61.7 to $80.2 \%$; however, only nests that had visible signs of hatchling emergence (about $80 \%$ ) and did not experience predation were included in this sample. This range is roughly comparable to our assessment of tics, such as marking 1 nest each day near a central work area. But this method would under-represent the middle of the season when nesting is greater and would over-represent the areas most convenient to access. Redundant nest marking is one way to ensure that nests are included in a sample even when storms erode the beach and when no hatchling emergence makes the nest conspicuous. We hypothesize that 'lost' sample nests are likely to have lower hatching and emergence success than other nests in the sample. As a result, a researcher forced to exclude lost nests will be left with an over-estimate of hatchling production. Because of this detection bias, we argue against the use of hatchling emergence evidence to locate a clutch for its inventory (Miller 1999).

Covariates from each sample nest were insufficient to explain interspecific differences in emergence success, but we noted 2 important factors worthy of future study. One is the seasonality of nesting. In Florida, leatherback nesting peaks in May (Stewart \& Johnson 2006), loggerhead nesting peaks in June and July (FWC's Fish and Wildlife Research Institute [FWRI] unpubl. data), and green turtle nesting peaks in July and August (FWRI unpubl. data). Because 
nesting seasons offset by only 1 mo can receive different nesting-beach erosion effects from tropical cyclones, we hypothesize that seasonality may predict nest survivorship. The 3 species also differ in elevation of nest placement on the beach, which has been shown to affect survivorship in loggerhead nests exposed to erosion by storms (Ehrhart \& Witherington 1987).

Although estimated annual hatchling production by each species correlated with annual statewide nest counts, certain years stood out as having strongly negative residuals (Fig. 4). We propose that this is due to important stochastic mortality factors that are independent of nest production, such as storm events. For example, 2004 was a year in which major hurricanes affected nesting beaches in southeast, southwest, and northwest Florida (NOAA National Weather Service, National Hurricane Center [NOAA NWS NHC]). That year, hatchling production for all 3 species was the lowest measured during the $11 \mathrm{yr}$ period (Fig. 4). This reduction was most pronounced for green turtles, whose nesting period extends the longest into the tropical cyclone season (NOAA NWS NHS). In an examination of loggerhead emergence success at the 16 study beaches (Fig. 3), 2004 stands out as having low nest survivorship at the majority of beaches. Similar low loggerhead nest survivorship occurred in 2005, which also was a year of numerous tropical cyclones.

\section{Factors affecting mortality and hatchling production}

Focusing on nest mortality factors is helpful in efforts to manage nesting beaches for increases in hatchling production. Mammalian predators, especially raccoons Procyon lotor, can significantly diminish success of a nest, but such nests are often omitted from hatching and emergence success calculations (Fowler 1979, Lagueux et al. 2003, Foley et al. 2006, Tapilatu \& Tiwari 2007) because of the difficulty in measuring the loss, i.e. an unknown number of eggs or hatchlings may be missing from a nest for which the original clutch size is also unknown. Nevertheless, these nests may still have hatching and emergence success rates greater than zero. Of the 2 principal sources of nest mortality we identified for Florida beaches, predation and erosion from storms, predation is the more manageable. We found that the predominant predators of Florida sea turtle eggs and hatchlings were mammals, principally raccoons, and ghost crabs (Fig. 6). Other predators and other mor- tality factors, contributing no more than $1 \%$ to egg and hatchling mortality, were ants, birds, plant roots, disturbance by another nesting turtle, and poaching. Although rates of nest predation would seem to indicate that ghost crabs had a large effect on egg mortality, very few nests preyed upon by ghost crab had been completely destroyed. For example, of the 2029 loggerhead nests affected by ghost crabs during the 11 yr study period, only 7 nests $(0.3 \%)$ had a hatching success rate of zero. By comparison, of 1673 loggerhead nests preyed on by mammals, 559 nests $(33 \%)$ were completely destroyed. Predation by ghost crabs reduced emergence success only $10 \%$ in loggerheads and $11 \%$ in green turtles, compared with nests with no reported mortality factors, although crab predation was more frequent than mammalian predation in all but the southwest region (Fig. 5). Emergence rates were comparable for loggerhead and green turtle nests that had been preyed on by mammals, as were the rates for those nests preyed on by ghost crabs.

Our analysis of the contribution of key mortality factors (Table 2) showed that complete washout from beach erosion and complete mammalian predation had the greatest effect on egg survivorship by reducing emergence success to zero. Beach erosion is an element of a larger suite of storm effects including nest wash over and inundation. These effects were likely encompassed by the category of partial erosion, which had the second-lowest emergence success (Table 2). From this we conclude that storm tides and accompanying erosion have profound effects on egg survivorship.

Our study beaches comprised an average of $43 \%$ of the nests in the Peninsular Florida Recovery Unit and $20 \%$ of the nests in the Northern Gulf of Mexico (Florida only) Recovery Unit beaches. Recovery goals specified in the Northwest Atlantic Loggerhead Recovery Plan (NMFS \& USFWS 2008) include an annual rate of nest predation by mammals of $<10 \%$ for all recovery units. In the present study, the annual nest predation rate by mammals for peninsular Florida ranged from 5.2 to $11.6 \%(\bar{x}=8.4 \%)$. For the 2 study beaches in the Florida panhandle, no mammalian predation was reported. But the total number of mammalian predation reports from SNBS beaches in the panhandle not included in this study ranged from 1 to 46 nests $\mathrm{yr}^{-1}(\bar{x}=4, \mathrm{n}=1291)$, so we conclude that this mortality factor was under-represented by our sampling in the panhandle. The 2 primary predators identified on panhandle beaches were raccoons and coyotes Canis latrans (FWRI unpubl. data). 

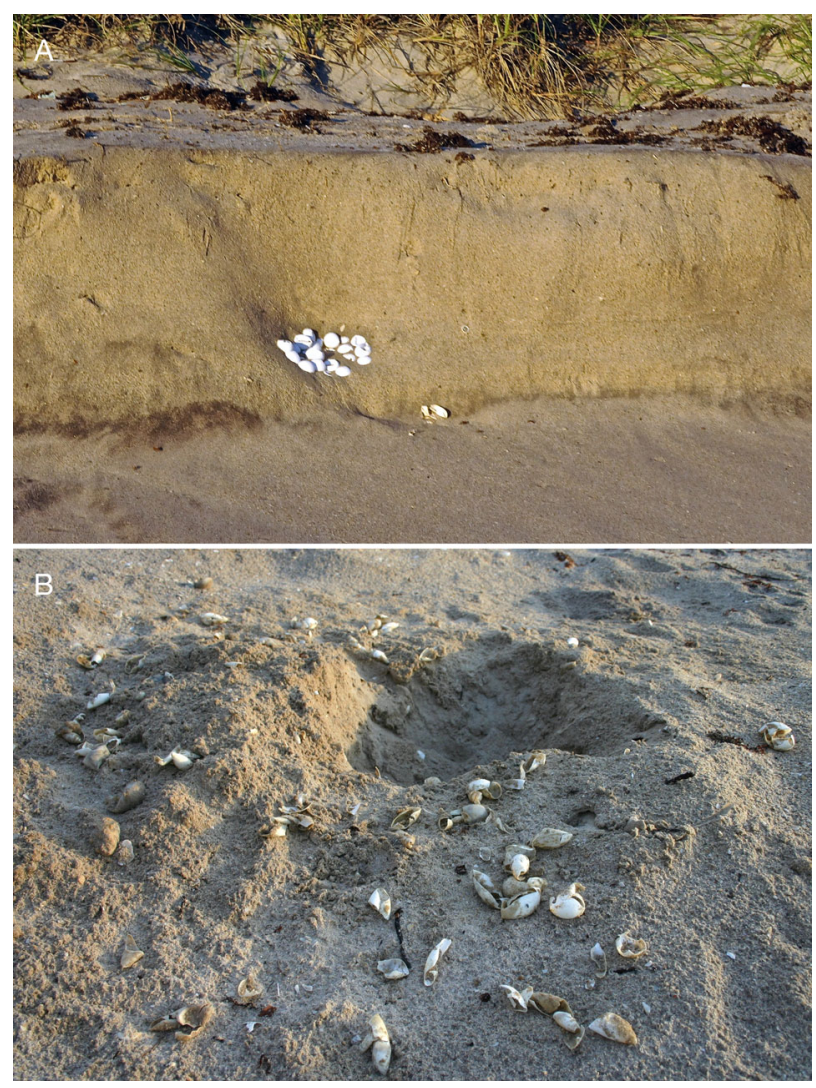

Fig. 6. Examples of potential mortality events affecting survivorship of sea turtle Caretta caretta hatchlings. The images show (A) the effects of erosion on a South Brevard County beach and (B) nest damage typical of predation by a raccoon

\section{RECOMMENDATIONS}

Hatching and emergence success rates are necessary for deriving estimates of egg-to-hatchling survivorship in sea turtle populations, but reported values for these rates can be misleading. It is often difficult for users of this information to understand definitions of reported values, how rates were determined, and how sample nests were selected. Subtleties in field techniques can create bias, and, where methods are not detailed, this bias may not be evident. We point to 4 important sources of biased estimates: (1) a misrepresentative distribution of sample nests in time and space, (2) lost nests, (3) special (deferential) treatment of sample nests, and (4) failure to consider or erroneous assumptions about nests subject to erosion or predation.

Although the assessment of egg survival and hatchling production would seem to be a straightforward estimation, we propose that this measurement is a complex challenge. Based on the present study, we make the following recommendations for future studies:

- Represent regional values for hatching success by including sample beaches from throughout the region. If a small fraction of regional beaches is sampled, these beaches should serve to represent unsampled beaches in terms of characteristics that influence mortality factors. These characteristics include similar mammalian predation and erosion rates.

- Choose sample nests that spatiotemporally represent each study area and nesting season. This choice should ensure that all nests in a study area have the same probability of being selected as a sample. This goal could be accomplished by the selection of every $n$th nest (see 'Materials and methods') during nest surveys throughout the study area and throughout the nesting season. When all nests on a beach can be carefully followed and inventoried, there is no need to adopt a sampling scheme.

- Conduct multiyear nest productivity assessments to capture variation among years. Three years may be sufficient, although a longer time series would be more likely to encompass stochastic mortality events such as storms and predator population spikes.

- Mark nest locations using a technique that ensures that the marks persist throughout the incubation period, even under conditions of dramatic changes in the beach. This will greatly reduce the number of sample nests with biased fates, such as those that cannot be found because nest markers cannot be located.

- Do not give preferential protection to sample nests. - Include all sample nests in the assessment of hatching and emergence success, including those that have been disturbed by erosion or predators. Knowledge of mortality factors associated with nests can be used to guide proxy values for hatching and emergence success (Table 2) where evidence has been destroyed. Average clutch sizes presented here can be used in these calculations to correct for unknown initial clutch sizes.

- Part of a regional nest sample should include nests with known clutch size so that lost hatchling production due to erosion and complete predation can be estimated. One way to sample true clutch size is to study fates of nests with eggs counted during translocation.

- More closely examine mortality from predators like ghost crabs that remove small numbers of eggs during incubation.

- Take an inventory of the contents of sample nests 3 to $5 \mathrm{~d}$ after the first sign of hatchling emergence 
(hatchlings may emerge over a $3 \mathrm{~d}$ period). This delay should be sufficient to allow viable hatchlings to emerge naturally but should minimize bias due to decomposition (additional fragmentation) of hatched eggshells and data loss from post-emergence destruction of nests by predators or storm erosion.

- Examine data distributions for an excessive number of zeros. Nonparametric methods and modeling based on zero-inflated probability distribution may be required for some analyses.

Careful observation and inventory of representative sample nests can give managers information for guiding the allocation of conservation resources and for measuring progress toward conservation goals. We recommend that managers assess the contribution of the different mortality factors before spending resources on nest protection or predator control. Such an assessment would support funding requests and track progress in achieving hatchling production goals.

Acknowledgements. Funding for Florida's sea turtle monitoring program has been provided by grants to the FWC under Project E-7 from the U.S. Fish and Wildlife Service and by proceeds from sales of the Florida marine turtle license plate. The SNBS program and database would not be possible without the dedication and hard work of hundreds of permit holders and volunteers who carry out beach surveys. We thank the following permit holders who contributed data for this paper: Bruce Drye (ANERR [Apalachicola National Estuarine Research Reserve] St. George Island Volunteer Turtlers), Suzi Fox (Anna Maria Island Turtle Watch), Elizabeth Golden (Bill Baggs Cape Florida State Park), Zoe Bass (Coastal Wildlife Club Inc.), Maura Kraus (Collier County Parks and Recreation), Erik Martin and Niki Desjardin (Ecological Associates Inc.), Scott Eastman (Guana Tolomato Matanzas National Estuarine Research Reserve), Kirt Rusenko (Gumbo Limbo Nature Center), Mike Bresette and Steve Weege (Inwater Research Group Inc.), Mike LeGare and Steven Trull (Merritt Island National Wildlife Refuge), Tony Tucker, Sarah Hirsch, and Kristen Mazzarella (Mote Marine Laboratory), and Kennard Watson (St. Andrew Bay Resource Management Association). We also thank the reviewers Jan Boyett, Bland Crowder, Allen Foley, Tomo Hirama, and Robbin Trindell.

\section{LITERATURE CITED}

> Abella E, Marco A, López-Jurado LF (2007) Success of delayed translocation of loggerhead turtle nests. J Wildl Manag 71:2290-2296

Blanck CE, Sawyer RH (1981) Hatchery practices in relation to early embryology of the loggerhead sea turtle, Caretta caretta (Linné). J Exp Mar Biol Ecol 49:163-177

Brennan LC (2013) Gulf oil spill. ABDO Publishing, Minneapolis, $\mathrm{MN}$

Conant TA, Dutton PH, Eguchi T, Epperly SP and others (2009) Loggerhead sea turtle (Caretta caretta) 2009 status review under the U.S. Endangered Species Act. Report of the Loggerhead Biological Review Team to the National Marine Fisheries Service. National Marine Fisheries Service, Silver Spring, MD

Eckert KL, Wallace BP, Frazier JG, Eckert SA, Pritchard $\mathrm{PCH}$ (2012) Synopsis of the biological data on the leatherback sea turtle (Dermochelys coriacea). Biological Technical Publication BTP-R4015-2012, US Fish and Wildlife Service, Washington, DC

Ehrhart LM, Witherington BE (1987) Human and natural causes of marine turtle nest and hatchling mortality and their relationship to hatchling production on an important Florida nesting beach. Technical Report No. 1, Florida Game and Fresh Water Fish Commission, Nongame Wildlife Program, Charleston, SC

Ehrhart LM, Bagley DA, Redfoot WE (2003) Loggerhead turtles in the Atlantic Ocean: geographic distribution, abundance, and population status. In: Bolten AB, Witherington BE (eds) Loggerhead sea turtles. Smithsonian Books, Washington, DC, p 157-174

Foley AM, Peck SA, Harman GR (2006) Effects of sand characteristics and inundation on the hatching success of loggerhead sea turtles (Caretta caretta) clutches on lowrelief mangrove islands in southwest Florida. Chelonian Conserv Biol 5:32-41

Fowler LE (1979) Hatching success and nest predation in the green sea turtle, Chelonia mydas, at Tortuguero, Costa Rica. Ecology 60:946-955

Hewavisenthi S, Parmenter CJ (2002) Incubation environment and nest success of the flatback turtle (Natator depressus) from a natural nesting beach. Copeia 302-312

Honarvar S, O'Connor MP, Spotila JR (2008) Density-dependent effects on hatching success of the olive ridley turtle, Lepidochelys olivacea. Oecologia 157:221-230

Lagueux CJ, Campbell CL, McCoy WA (2003) Nesting and conservation of the hawksbill turtle, Eretmochelys imbricata, in the Pearl Cays, Nicaragua. Chelonian Conserv Biol 4:588-602

Margaritoulis D (2005) Nesting activity and reproductive output of loggerhead sea turtles, Caretta caretta, over 19 seasons (1984-2002) at Laganas Bay, Zakynthos, Greece: the largest rookery in the Mediterranean. Chelonian Conserv Biol 4:916-929

Miller J (1999) Determining clutch size and hatching success. In: Eckert KL, Bjorndal KA, Abreu-Grobois FA, Donnelly M (eds) Research and management techniques for the conservation of sea turtles. Publication No. 4, IUCN/SSC Marine Turtle Specialist Group, Blanchard, PA, p 124-129

Niethammer KR, Balazs GH, Hatfield JS, Nakai GL, Megyesi JL (1997) Reproductive biology of the green turtle (Chelonia mydas) at Tern Island, French Frigate Shoals, Hawaii. Pac Sci 51:36-47

NMFS \& USFWS (National Marine Fisheries Service and U.S. Fish and Wildlife Service) (2008) Recovery plan for the Northwest Atlantic population of the loggerhead sea turtle (Caretta caretta), 2nd rev. National Marine Fisheries Service, Silver Spring, MD

Ozdemir B, Turkozan O (2006) Hatching success of original and hatchery nests of the green turtle, Chelonia mydas, in northern Cyprus. Turk J Zool 30:377-381

Pérez-Castañeda R, Salum-Fares A, Defeo O (2007) Reproductive patterns of the hawksbill turtle Eretmochelys imbricata in sandy beaches of the Yucatan Peninsula. J Mar Biol Assoc UK 87:815-824 
Pike DA, Stiner JC (2007) Fluctuating reproductive output and environmental stochasticity: Do years with more reproducing females result in more offspring? Can J Zool 85:737-742

Seminoff J (2002) IUCN red list global status assessment, green turtle Chelonia mydas. Marine Turtle Specialist Group, The World Conservation Union (IUCN), Species Survival Commission, Red List Programme, Cambridge

Steinitz MJ, Salmon M, Wyneken J (1998) Beach renourishment and loggerhead turtle reproduction: a seven year study at Jupiter Island. Florida. J Coast Res 14:1000-1013

Stewart K, Johnson C (2006) Dermochelys coriacea, leatherback sea turtle. In: Meylan PA (ed) Biology and conservation of Florida turtles. Chelonian Research Monographs 3. Chelonian Research Foundation, Lunenburg, MA, p 144-157

Stewart K, Sims M, Meylan A, Witherington B, Brost B, Crowder L (2011) Leatherback nests increasing significantly in Florida, USA; trends assessed over 30 years using multilevel modeling. Ecol Appl 21:263-273

Tapilatu RF, Tiwari M (2007) Leatherback turtle, Dermochelys coriacea, hatching success at Jamursba-Medi and

Editorial responsibility: Matthew Godfrey,

Beaufort, North Carolina, USA
Wermon beaches in Papua, Indonesia. Chelonian Conserv Biol 6:154-158

Tuttle J, Rostal D (2010) Effects of nest relocation on nest temperature and embryonic development of loggerhead sea turtles (Caretta caretta). Chelonian Conserv Biol 9:1-7

Van de Merwe J, Ibrahim K, Whittier J (2005) Effects of hatchery shading and nest depth on the development and quality of Chelonia mydas hatchlings: implications for hatchery management in peninsular Malaysia. Aust J Zool 53:205-211

Witherington B, Bresette M, Herron R (2006a) Chelonia mydas, green turtle. In: Meylan PA (ed) Biology and conservation of Florida turtles. Chelonian Research Monographs 3. Chelonian Research Foundation, Lunenburg, MA, p 90-104

Witherington B, Herron R, Bresette M (2006b) Caretta caretta, loggerhead sea turtle. In: Meylan PA (ed) Biology and Conservation of Florida Turtles. Chelonian Research Monographs 3. Chelonian Research Foundation, Lunenburg, MA, p 74-89

Witherington B, Kubilis P, Brost B, Meylan A (2009) Decreasing annual nest counts in a globally important loggerhead sea turtle population. Ecol Appl 19:30-54

Submitted: March 10, 2014; Accepted: October 9, 2014

Proofs received from author(s): December 17, 2014 